\title{
Low Urine pH Is a Predictor of Chronic Kidney Disease
}

\author{
Naoko Nakanishi ${ }^{a}$ Michiaki Fukui ${ }^{a}$ Muhei Tanaka ${ }^{a}$ Hitoshi Toda ${ }^{c}$ Saeko Imai ${ }^{d}$ \\ Masahiro Yamazaki ${ }^{a}$ Goji Hasegawa ${ }^{a}$ Yohei Oda $^{b}$ Naoto Nakamura ${ }^{a}$ \\ Departments of ${ }^{\mathrm{a}}$ Endocrinology and Metabolism and ${ }^{\mathrm{b}}$ Immunology and Inflammation, Kyoto Prefectural \\ University of Medicine, Graduate School of Medical Science, and ' Department of Internal Medicine, \\ Sakazaki Clinic, Kyoto, and d Department of Clinical Nutrition, Faculty of Comprehensive Rehabilitation, \\ Osaka Prefecture University, Osaka, Japan
}

\section{Key Words}

Acidic urine $\cdot$ Low urine $\mathrm{pH} \cdot$ Chronic kidney disease

\begin{abstract}
Background/Aims: A variety of risk factors for chronic kidney disease (CKD), including the metabolic syndrome, were recently reported. It has been suggested that a low urine $\mathrm{pH}$ is another characteristic of the metabolic syndrome. However, the relationship between urine $\mathrm{pH}$ and CKD remains to be elucidated. Methods: A cohort study was performed on 1,811 subjects who underwent a health check-up, and we examined whether low urine $\mathrm{pH}$ could be a predictor of CKD. The following risk factors for CKD were evaluated: age, gender, history of alcohol intake and smoking, BMI, systolic blood pressure, fasting plasma glucose, total cholesterol, uric acid, total leukocyte count, CKD stage, fasting urine $\mathrm{pH}$, and protein at baseline. Results: We followed 1,811 subjects for a median period of 7.7 years. Three hundred and thirtynine subjects developed stage 3 CKD defined as progression to estimated glomerular filtration rate $<60 \mathrm{ml} / \mathrm{min} / 1.73 \mathrm{~m}^{2}$. Multiple Cox regression analysis revealed that the adjusted HR (95\% Cl) for stage 3 CKD was $1.32(1.06-1.65 ; p=0.0129)$ in subjects with fasting urine $\mathrm{pH}$ 5.0-5.5 compared to subjects with $\mathrm{pH}$ 6.5-7.0. Conclusion: Our study suggests that low urine $\mathrm{pH}$ is an independent predictor of stage 3 CKD.
\end{abstract}

Copyright $\odot 2011$ S. Karger AG, Basel

\section{Introduction}

Chronic kidney disease (CKD) is increasingly recognized as public health problem [1]. A recent study demonstrated that estimated glomerular filtration rate (eGFR) $<60 \mathrm{ml} / \mathrm{min} / 1.73 \mathrm{~m}^{2}$ independently predicts the risk for cardiovascular events and hospitalization [2]. It was also recently described that CKD is associated with the metabolic syndrome (MS), which is also known as the insulin resistance syndrome, characterized by a constellation of metabolic features including dyslipidemia, hyperglycemia, hypertension and obesity [3-5]. Additionally, recent reports have suggested that low urine $\mathrm{pH}$ is another characteristic of MS or insulin-resistant individuals $[6,7]$.

However, the relationship between urine $\mathrm{pH}$ and CKD remains to be elucidated. To determine whether low urine $\mathrm{pH}$ can be the predictor of CKD, we examined data of a large community-based cohort of adults.

\section{Materials and Methods}

Subjects and Study Design

The Sakazaki Health Survey is an ongoing cohort investigation of risk factors for chronic diseases, including hypertension, diabetes and CKD. The Sakazaki Clinic (Kyoto, Japan) provides regular health check-up for employees. In Japan, yearly routine examinations for employees is legally mandated, and all or most

\section{KARGER}

Fax +4161306 1234 E-Mail karger@karger.ch www.karger.com
(C) 2011 S. Karger AG, Basel

$1420-4096 / 12 / 0352-0077 \$ 38.00 / 0$

Accessible online at:

www.karger.com/kbr
Michiaki Fukui, MD, PhD

Department of Endocrinology and Metabolism

Kyoto Prefectural University of Medicine, Graduate School of Medical Science 465 Kajii-cho, Kawaramachi-Hirokoji, Kamigyo-ku, Kyoto 602-8566 (Japan)

Tel. +81 75251 5505, E-Mail sayarinapm@ @otmail.com 
Table 1. Baseline characteristics of subjects

\begin{tabular}{|c|c|c|c|c|c|}
\hline & All & pH 5.0-5.5 & pH 6.0 & pH 6.5-7.0 & $\mathrm{p}$ value \\
\hline Number of subjects & 1,811 & 795 & 597 & 419 & \\
\hline Age, year & $45.5 \pm 10.2$ & $45.7 \pm 9.8$ & $44.5 \pm 10.2$ & $46.5 \pm 10.8$ & 0.0057 \\
\hline Male & $1,107(61.1)$ & $491(61.8)$ & $364(61.0)$ & $252(60.1)$ & 0.8559 \\
\hline Smoking & $323(17.8)$ & $176(22.1)$ & $106(17.8)$ & $41(9.8)$ & $<0.0001$ \\
\hline Alcohol & $661(36.5)$ & $304(38.2)$ & $219(36.7)$ & $138(32.9)$ & 0.1880 \\
\hline BMI & $22.6 \pm 3.1$ & $22.7 \pm 3.2$ & $22.3 \pm 3.1$ & $22.7 \pm 3.0$ & 0.0189 \\
\hline $\mathrm{SBP}, \mathrm{mm} \mathrm{Hg}$ & $117.2 \pm 16.6$ & $116.4 \pm 16.0$ & $116.5 \pm 16.7$ & $119.7 \pm 17.3$ & 0.0021 \\
\hline Fasting plasma glucose, $\mathrm{mmol} / \mathrm{l}$ & $5.2 \pm 1.1$ & $5.3 \pm 1.3$ & $5.1 \pm 0.9$ & $5.1 \pm 0.7$ & 0.0023 \\
\hline Total cholesterol, mmol/l & $5.3 \pm 0.9$ & $5.4 \pm 0.9$ & $5.2 \pm 0.9$ & $5.3 \pm 0.9$ & 0.0152 \\
\hline Uric acid, $\mu \mathrm{mol} / \mathrm{l}$ & $321.0 \pm 82.3$ & $327.7 \pm 85.3$ & $318.2 \pm 80.8$ & $312.5 \pm 77.8$ & 0.0052 \\
\hline Total leukocyte count, $\times 10^{9} / 1$ & $5.6 \pm 1.6$ & $5.7 \pm 1.7$ & $5.5 \pm 1.6$ & $5.4 \pm 1.4$ & 0.0090 \\
\hline CKD stage 2 & $1,643(90.7)$ & $732(92.1)$ & $537(90.0)$ & $374(89.3)$ & 0.2001 \\
\hline Baseline GFR, $\mathrm{ml} / \mathrm{min} / 1.73 \mathrm{~m}^{2}$ & $75.8 \pm 11.1$ & $75.1 \pm 11.1$ & $76.4 \pm 11.1$ & $76.3 \pm 11.2$ & 0.0711 \\
\hline Proteinuria & $72(4.0)$ & $31(3.9)$ & $32(5.4)$ & $9(2.2)$ & 0.0355 \\
\hline
\end{tabular}

Values are means \pm SD or $\mathrm{n}(\%)$.

of the costs for the health check-up are usually paid by their employers. Between 1998 and 2003, 2,273 Japanese subjects were enrolled in the study. We excluded 352 subjects who were stage 3-5 CKD at baseline. Subjects with urine $\mathrm{pH}>7.5$ were also excluded because we considered abnormally high $\mathrm{pH}$ as being affected by a urinary tract infection. At the time of urine evaluation, none of the subjects were taking any medications known to alter urine $\mathrm{pH}$ such as potassium alkali, sodium bicarbonate or carbonic anhydrase inhibitors. We followed up 1,811 subjects and evaluated the risk factors for $\mathrm{CKD}$ and assessed whether low urine $\mathrm{pH}$ could predict CKD. Approval for all studies was obtained from the Ethical Committee of Sakazaki Clinic, and the study was conducted in accordance with Declaration of Helsinki. Written informed consent was obtained from each subject.

\section{Data Collection and Measurements}

All subjects provided details of their demographics. Smoking was defined as current tobacco usage. History of alcohol was defined as daily alcohol consumption. BMI was calculated as weight in kilograms divided by height in meters squared. After an overnight fast, venous blood was collected for the measurement of the levels of various factors, including fasting plasma glucose, total cholesterol, uric acid (UA) and total leukocyte count. GFR was estimated using the Japanese Society of Nephrology equation: $\mathrm{eGFR}=194 \times \mathrm{Cre}^{-1.094} \times \mathrm{age}^{-0.287}\left(\mathrm{ml} / \mathrm{min} / 1.73 \mathrm{~m}^{2}\right)[8]$. For women, the eGFR was multiplied by a correction factor of 0.739 . CKD staging was based on the level of eGFR. Stage 1, stage 2 and stage $3 \mathrm{CKD}$ were defined as eGFR $>90,60-89$ and $<60 \mathrm{ml} /$ $\mathrm{min} / 1.73 \mathrm{~m}^{2}$, respectively. Proteinuria was determined using dipstick testing in fasting morning urine (positive: $1+$ or greater). We measured urine $\mathrm{pH}$ by the indicator method using a dipstick ( $\mathrm{Yu}$ rifuret-S and Aution-analyzer; Arkray, Kyoto, Japan). The available range was from pH 5.0 to $\mathrm{pH} 9.0$ in $0.5 \mathrm{pH}$ unit increments. The urine was not collected under oil, and we measured urine $\mathrm{pH}$ values immediately after the fasting morning urine sample was obtained.

\section{Statistical Analysis}

The statistical analyses were performed using the JMP version 8.0 software (SAS Institute Inc., Cary, N.C., USA). $\mathrm{p}<0.05$ was considered statistically significant. Continuous variables are presented as the mean value $\pm 1 \mathrm{SD}$ and categorical variables are presented as number (\%). Categorical and continuous variables were compared among the groups by a $\chi^{2}$ analysis and analysis of variance (ANOVA), respectively. We evaluated the predictor for stage $3 \mathrm{CKD}$ by univariate and multiple Cox regression analysis to adjust for covariates including age, gender, history of alcohol intake and smoking, BMI, systolic blood pressure (SBP), fasting plasma glucose, total cholesterol, UA, total leukocyte count, CKD stage, fasting urine protein, and $\mathrm{pH}$ at baseline.

\section{Results}

A total of 1,811 subjects were followed up for a median period of 7.7 years in this study. The baseline characteristics are shown in table 1 . There were 704 females and 1,107 males, aged $45.5 \pm 10.2$ years. All of the subjects were classified into three groups according to fasting urine pH: 5.0-5.5, 6.0 and 6.5-7.0. Each group was followed for a median period of 7.6 years with $\mathrm{pH}$ 5.0-5.5, 8.0 years with $\mathrm{pH} 6.0$ and 7.6 years with $\mathrm{pH}$ 6.5-7.0, respectively. Compared with the subjects with higher urine $\mathrm{pH}$, the subjects with lower urine $\mathrm{pH}$ had lower SBP $(\mathrm{p}=$ $0.0021)$, higher fasting plasma glucose $(\mathrm{p}=0.0023)$, higher UA $(p=0.0052)$ and a higher total leukocyte count $(\mathrm{p}=0.0090)$, and were likely to be a current smoker $(\mathrm{p}<$ $0.0001)$. One hundred and sixty-nine subjects $(21.3 \%)$ with urine $\mathrm{pH} 5.0-5.5,98$ subjects (16.4\%) with urine $\mathrm{pH}$ 
Table 2. Predictors of stage 3 CKD by Cox regression analysis

\begin{tabular}{|c|c|c|c|c|}
\hline \multirow[t]{2}{*}{ Variables } & \multicolumn{2}{|c|}{ Univariate Cox regression analysis } & \multicolumn{2}{|c|}{ Multiple Cox regression analysis } \\
\hline & $\operatorname{HR}(95 \% \mathrm{CI})$ & $\mathrm{p}$ value & $\mathrm{HR}(95 \% \mathrm{CI})$ & $\mathrm{p}$ value \\
\hline Age, per 10 years & $1.87(1.74-2.00)$ & $<0.0001$ & $1.81(1.67-1.96)$ & $<0.0001$ \\
\hline Male, yes & $1.11(0.95-1.30)$ & 0.1815 & $0.76(0.61-0.95)$ & 0.0151 \\
\hline Smoking, yes & $0.74(0.60-0.92)$ & 0.0059 & $0.88(0.68-1.12)$ & 0.3142 \\
\hline Alcohol, yes & $0.91(0.77-1.06)$ & 0.2217 & $0.85(0.71-1.01)$ & 0.0609 \\
\hline BMI, per 1.0 increase & $1.07(1.05-1.10)$ & $<0.0001$ & $1.02(0.99-1.06)$ & 0.1185 \\
\hline SBP, per $10-\mathrm{mm} \mathrm{Hg}$ increase & $1.15(1.11-1.20)$ & $<0.0001$ & $0.99(0.94-1.05)$ & 0.8289 \\
\hline Fasting plasma glucose, per $1.0-\mathrm{mmol} / \mathrm{l}$ increase & $1.11(1.04-1.16)$ & 0.0017 & $0.94(0.86-1.02)$ & 0.1317 \\
\hline Total cholesterol, per $1.0-\mathrm{mmol} / \mathrm{l}$ increase & $1.29(1.19-1.39)$ & $<0.0001$ & $1.02(0.93-1.12)$ & 0.7011 \\
\hline Uric acid, per $10.0-\mu \mathrm{mol} / \mathrm{l}$ increase & $1.00(1.00-1.01)$ & $<0.0001$ & $1.04(1.03-1.05)$ & $<0.0001$ \\
\hline Total leukocyte count, $\% \times 10^{6} / 1$ increase & $1.02(0.97-1.07)$ & 0.4590 & $0.99(0.93-1.05)$ & 0.6981 \\
\hline \multicolumn{5}{|l|}{ CKD } \\
\hline Stage 1 (reference) & 1.0 & & 1.0 & \\
\hline Stage 2 & $4.09(2.89-5.26)$ & $<0.0001$ & $3.73(2.62-4.91)$ & $<0.0001$ \\
\hline \multicolumn{5}{|l|}{ Proteinuria } \\
\hline$(-)$ or $( \pm)$ (reference) & 1.0 & & 1.0 & \\
\hline$(+)$ & $1.31(0.92-1.80)$ & 0.1342 & $1.33(0.89-1.90)$ & 0.1537 \\
\hline \multicolumn{5}{|l|}{ Urine $\mathrm{pH}$} \\
\hline $5.0-5.5$ & $1.26(1.03-1.54)$ & 0.0221 & $1.32(1.06-1.65)$ & 0.0129 \\
\hline 6.0 & $1.03(0.84-1.29)$ & 0.7414 & $1.17(0.93-1.49)$ & 0.1895 \\
\hline $6.5-7.0$ (reference) & 1.0 & & 1.0 & \\
\hline
\end{tabular}

6.0 and 72 subjects with $\mathrm{pH}$ 6.5-7.0 (17.2\%) developed stage $3 \mathrm{CKD}$ during the period. Cox regression analysis was performed to assess risk factors for stage $3 \mathrm{CKD}$ (table 2). Univariate Cox regression analysis demonstrated that age, history of smoking, BMI, SBP, fasting plasma glucose, total cholesterol, UA, CKD stage and urine $\mathrm{pH}$ were associated with progression of stage 3 CKD. Multiple Cox regression analysis revealed that the adjusted HR (95\% CI) for stage 3 CKD was 1.32 (1.06-1.65; p = $0.0129)$ in subjects with fasting urine $\mathrm{pH} 5.0-5.5 \mathrm{com}-$ pared with subjects with fasting urine $\mathrm{pH}$ 6.5-7.0. Age, gender, UA and CKD stage at baseline were also independent predictors of stage $3 \mathrm{CKD}$ after adjustment for $\mathrm{Co}^{-}$ variates.

\section{Discussion}

Our study demonstrated that low urine $\mathrm{pH}$ was an independent predictor of stage 3 CKD. Recent studies reported that CKD was associated with increased cardiovascular disease and all-cause mortality $[9,10]$. Therefore, it is important to identify a predictor of CKD. To our knowledge, this is the first report to reveal the relationship between urine $\mathrm{pH}$ and progression of CKD.
It was recently described that CKD was associated with MS [3, 4]. In addition, others have speculated that insulin resistance, hyperinsulinemia and inflammation resulting from lipotoxicity have a direct role in increasing excretory load and aggravating tubulointerstitial damage $[11,12]$. Several reports have shown that low urine $\mathrm{pH}$ was associated with MS [6, 7] and obesity [13, 14]. It was also demonstrated that 24 -hour urine $\mathrm{pH}$ is correlated to MS, and an inverse relationship was noted between urine $\mathrm{pH}$ and homeostasis model assessment-insulin resistance [7]. This concept is supported by a pathophysiological mechanism in which insulin influences renal production or excretion of ammonium, which is an important urinary buffer [15-18] and that insulin resistance is associated with defective renal ammoniagenesis [7]. Taking these findings together, MS and insulin resistance link to both urine $\mathrm{pH}$ and CKD progression, and it seems plausible that low urine $\mathrm{pH}$ is an independent predictor of stage 3 CKD.

We also demonstrated that hyperuricemia was associated with an increased risk for incident CKD in this study. The association between UA and CKD has gained some support from previous studies. Recent epidemiologic evidence suggested a significant and independent association between the level of serum UA and renal disease pro- 
gression with beneficial effect of decreasing UA levels [19, 20]. In rats, hyperuricemia increased SBP, proteinuria, renal dysfunction, vascular disease and progressive renal scarring by a crystal-independent mechanism [21]. Recent data also suggested hyperuricemia might be the key component of the activation of the renin-angiotensin and cyclooxygenase- 2 systems in progressive renal disease [22].

We obtained the results that both low urine $\mathrm{pH}$ and hyperuricemia were associated with progression of CKD and that subjects with low urine $\mathrm{pH}$ had a higher UA level. However, low urine $\mathrm{pH}$ was a predictor of CKD independent of UA by multiple Cox regression analysis.

This study has several strengths, which include the large community-based sample and long duration of follow-up. Nevertheless, several limitations may affect the interpretation of these results. First, we have used eGFR $<60 \mathrm{ml} / \mathrm{min} / 1.73 \mathrm{~m}^{2}$ as a clinical endpoint rather than urinary protein excretion. This was supported by reports that a reduced eGFR is associated with increased risks of death, cardiovascular events and hospitalization, which was independent of the presence of documented proteinuria $[2,23]$. Second, in this study, the mechanism of kidney injury caused by acidic urine was not elucidated. Lin et al. [24] demonstrated that increased intake of red meat was associated with microalbuminuria, suggesting high intake of animal protein (dietary acid) promotes renal damage. Evaluating urine components (sulfate, potassium, urine net acid excretion and ammonium) and contents of meals is valuable for identifying the causes of acidic urine. However, we believe it is noteworthy that low urine $\mathrm{pH}$ could be a predictor of CKD in the outpatient and routine medical check-up settings. Third, we used single, not 24-hour collected, fasting urine to measure urine $\mathrm{pH}$. Although the finding of diurnal variation has been confirmed, Capolongo et al. [25] demonstrated fasting urine $\mathrm{pH}$ correlates significantly with 24-hour urine $\mathrm{pH}$ for the entire cohort. Additionally, we measured urine $\mathrm{pH}$ by the indicator method using a dipstick rather than electrodes. Measurement of urine $\mathrm{pH}$ by the indicator method is less reliable than by electrodes; however, the indicator method might be appropriate for health checkup in terms of its convenience and cost savings. Moreover, in the previous study, the accuracy of urinary dipstick testing for $\mathrm{pH}$ manipulation therapy was assessed by comparing three commercial brands of dipstick paper and electrodes, revealing dipstick testing to be accurate [26].

Our study is in the line with a recent study showing daily sodium bicarbonate is an effective kidney protective adjunct to blood pressure control in hypertensive nephropathy [27]. Further investigation is warranted to elucidate the relationship between urine alkalization and the protective effect against CKD.

\section{Conclusions}

We have demonstrated that low urine $\mathrm{pH}$ is an independent predictor of CKD. Above all, we suggest that examination of the fasting urine $\mathrm{pH}$ can be a practical screening tool for CKD and that it is beneficial in recognizing the segment of the population who have acidic urine.

\section{Acknowledgement}

We thank Ms. Mayumi Kitano for collecting subject data.

\section{References}

metabolic syndrome and chronic kidney disease in U.S. adults. Ann Intern Med 2004; 140:167-174. A, Eckardt KU, Nahas ME, Jaber BI Wheeler DC, Lameire N, Eknoyan G: Chronic kidney disease as a global public health problem: approaches and initiatives - a position statement from Kidney Disease Improving Global Outcomes. Kidney Int 2007;72: 247-259.

2 Go AS, Chertow GM, Fan D, McCulloch CE, Hsu CY: Chronic kidney disease and the risks of death, cardiovascular events, and hospitalization. N Engl J Med 2004;351: 1296-1305.

3 Chen J, Muntner P, Hamm LL, Jones DW, Batuman V, Fonseca V, Whelton PK, He J: The
4 Kurella M, Lo JC, Chertow GM: Metabolic syndrome and the risk for chronic kidney disease among nondiabetic adults. J Am Soc Nephrol 2005;16:2134-2140.

5 Eckel RH, Grundy SM, Zimmet PZ: The metabolic syndrome. Lancet 2005;365:14151428

-6 Takahashi S, Inokuchi T, Kobayashi T, Ka T, Tsutsumi Z, Moriwaki Y, Yamamoto T: Relationship between insulin resistance and low urinary $\mathrm{pH}$ in patients with gout, and effects of PPAR alpha agonists on urine $\mathrm{pH}$. Horm Metab Res 2007;39:511-514. 
7 Maalouf NM, Cameron MA, Moe OW, Adams-Huet B, Sakhaee K: Low urine $\mathrm{pH}$ : a novel feature of the metabolic syndrome. Clin J Am Soc Nephrol 2007;2:883-888.

$\checkmark 8$ Matsuo S, Imai E, Horio M, Yasuda Y, Tomita K, Nitta K, Yamagata K, Tomino Y, Yokoyama H, Hishida A: Collaborators developing the Japanese equation for estimated GFR. Revised equations for estimated GFR from serum creatinine in Japan. Am J Kidney Dis 2009;53:982-992.

-9 Manjunath G, Tighiouart H, Coresh J, Macleod B, Salem DN, Griffith JL, Levey AS, Sarnak MJ: Level of kidney function as a risk factor for cardiovascular outcomes in the elderly. Kidney Int 2003;63:1121-1129.

-10 Nakamura K, Okamura T, Hayakawa T, Kadowaki T, Kita Y, Ohnishi H, Saitoh S, Sakata K, Okayama A, Ueshima H, NIPPON DATA90 Research Group: Chronic kidney disease is a risk factor for cardiovascular death in a community-based population in Japan: NIPPON DATA90. Circ J 2006;70: 954-999.

-11 Cusumano AM, Bodkin NL, Hansen BC, Iotti R, Owens J, Klotman PE, Kopp JB: Glomerular hypertrophy is associated with hyperinsulinemia and precedes overt diabetes in aging rhesus monkeys. Am J Kidney Dis 2002;40:1075-1085.

-12 Kamijo A, Kimura K, Sugaya T, Yamanouchi M, Hase H, Kaneko T, Hirata Y, Goto A, Fujita T, Omata M: Urinary free fatty acids bound to albumin aggravate tubulointerstitial damage. Kidney Int 2002;62:1628-1637.
13 Maalouf NM, Sakhaee K, Parks JH, Coe FL, Adams-Huet B, Pak CY: Association of urinary $\mathrm{pH}$ with body weight in nephrolithiasis. Kidney Int 2004;65:1422-1425.

14 Taylor EN, Curhan GC: Body size and 24hour urine composition. Am J Kidney Dis 2006;48:905-915.

15 DuBose TD Jr, Good DW, Hamm LL, Wall SM: Ammonium transport in the kidney: New physiological concepts and their clinical implications. J Am Soc Nephrol 1991;1: 1193-1203.

16 Agarwal BN, Cabebe FG: Renal acidification in elderly subjects. Nephron 1980;26:291295.

-17 Nissim I, States B, Nissim I, Lin ZP, Yudkoff M: Hormonal regulation of glutamine metabolism by OK cells. Kidney Int 1975;47: 96-105.

18 Klisic J, Hu MC, Nief V, Reyes L, Fuster D, Moe OW, Ambühl PM: Insulin activates $\mathrm{Na}+/ \mathrm{H}+$ exchanger 3: biphasic response and glucocorticoid dependence. Am J Physiol Renal Physiol 2002;283:532-539.

19 Tomita M, Mizuno S, Yamanaka H, Hosoda Y, Sakuma K, Matuoka Y, Odaka M, Yamaguchi M, Yosida $\mathrm{H}$, Morisawa $\mathrm{H}$, Murayama T: Does hyperuricemia affect mortality? A prospective cohort study of Japanese male workers. J Epidemiol 2000;10:403-409. 20 Iseki K, Ikemiya Y, Inoue T, Iseki C, Kinjo K,
Takishita S: Significance of hyperuricemia as a risk factor for developing ESRD in a screened cohort. Am J Kidney Dis 2004;44: 642-650.
21 Mazzali M, Hughes J, Kim YG, Jefferson JA, Kang D-H, Gordon KL, Lan HY, Kivlighn S, Johnson RJ: Elevated uric acid increases blood pressure in the rat by a novel crystalindependent mechanism. Hypertension 2001; 38:1101-1106.

-22 Kang DH, Nakagawa T, Feng L, Watanabe S, Han L, Mazzali M, Truong L, Harris R, Johnson RJ: A role for uric acid in the progression of renal disease. J Am Soc Nephrol 2002;13: 2888-2897.

-23 Kiyosue A, Hirata Y, Ando J, Fujita H, Morita T, Takahashi M, Nagata D, Kohro T, Imai Y, Nagai R: Relationship between renal dysfunction and severity of coronary artery disease in Japanese patients. Circ J 2010;74:786791.

24 Lin J, Fung TT, Hu FB, Curhan GC: Association of dietary patterns with albuminuria and kidney function decline in older white women: a subgroup analysis from the Nurses' Health Study. Am J Kidney Dis 2011;57: 245-254.

25 Capolongo G, Sakhaee K, Pak CY, Maalouf NM: Fasting versus 24-hour urine $\mathrm{pH}$ in the evaluation of nephrolithiasis. Urol Res 2011, E-pub ahead of print.

26 Desai RA, Assimos DG: Accuracy of urinary dipstick testing for $\mathrm{pH}$ manipulation therapy. J Endourol 2008;22:1367-1370.

27 Mahajan A, Simoni J, Sheather SJ, Broglio KR, Rajab MH, Wesson DE: Daily oral sodium bicarbonate preserves glomerular filtration rate by slowing its decline in early hypertensive nephropathy. Kidney Int 2010;78: 303-309. 